\title{
DAMPAK KEMIRINGAN KOLEKTOR SURYA BATU GRANIT TERHADAP UNJUK KERJA
}

\author{
M. Mirmanto \\ Jurusan Teknik Mesin, Fakultas Teknik \\ Universitas Mataram \\ Email:m.mirmanto@unram.ac.id \\ Made Wirawan \\ Jurusan Teknik Mesin, Fakultas Teknik \\ Universitas Mataram \\ Imam Fahrurrozi \\ Jurusan Teknik Mesin, Fakultas Teknik \\ Universitas Mataram
}

\begin{abstract}
ABSTRAK
Percobaan untuk mengetahui dampak kemiringan kolektor surya telah dilakukan. Percobaan ini menggunakan kolektor surya dengan batu granit sebagai absorbernya. Ukuran kolektor yang digunakan adalah $100 \mathrm{~cm} \times 80 \mathrm{~cm} \times 10 \mathrm{~cm}$ dengan saluran paralel yang terbuat dari tujuh pipa tembaga. Kemiringan sudut kolektor yang divariasikan adalah $15^{\circ}, 30^{\circ}$ dan $45^{\circ}$ dan debit aliran air yang diterapkan adalah 300 , 400, dan $500 \mathrm{cc} /$ menit. Pengambilan data dilakukan tiap 30 menit, sedangkan pengecekan debit aliran dilakukan tiap 10 menit. Lama total percobaan adalah 7 jam yaitu dari jam 10.00 Wita sampai jam 17.00 Wita. Hasil penelitian menunjukkan bahwa beda suhu air masuk dan keluar tertinggi didominasi oleh kolektor surya dengan kemiringan $30^{\circ}$ yaitu sekitar $17,64^{\circ} \mathrm{C}$ pada debit $300 \mathrm{cc} /$ menit. Sementara itu, untuk kemiringan $15^{\circ}$ dan $45^{\circ}$, selisih temperatur yang diperoleh sebesar $16,11^{\circ} \mathrm{C}$ dan $15,91{ }^{\circ} \mathrm{C}$. Namun demikian, efisiensi rata-rata tertinggi sebesar $64,44 \%$ diperoleh pada sudut kemiringan kolektor $30^{\circ}$ dan debit $400 \mathrm{cc} / \mathrm{menit}$.
\end{abstract}

Kata kunci: sudut kolektor; debit aliran; beda suhu; efisiensi.

\begin{abstract}
Experiments to know the effect of the solar collector angle on the collector performance have been done. The experiments used three identical flat plate solar collectors with granite stones as their absorbers. The overall collector size was $100 \mathrm{~cm} \times 80 \mathrm{~cm} \times 10 \mathrm{~cm}$ with a parallel channel made of seven copper pipes. The variation of the collector angles was $15^{\circ}, 30^{\circ}$ and $45^{\circ}$ and the water discharges used were 300, 400, and $500 \mathrm{cc} / \mathrm{min}$. The data were collected at every 30 minutes, while the flow discharge was checked at every 10 minutes. The total time of the experiment was 7 hours, from 10.00 Wita to 17.00 Wita. The results showed that the highest temperature difference of water at the inlet and outlet was dominated by the solar collector with the inclination angle of $30^{\circ}$. That was of approximately $17.64^{\circ} \mathrm{C}$ at the discharge of $300 \mathrm{cc} / \mathrm{min}$. Meanwhile, for the inclination angle of $15^{\circ}$ and $45^{\circ}$, the resulting temperature differences were $16.11^{\circ} \mathrm{C}$ and $15.91^{\circ} \mathrm{C}$. However, the highest average efficiency of $64.44 \%$ was obtained by the collector with the inclination angle of $30^{\circ}$ and the discharge of $400 \mathrm{cc} / \mathrm{min}$.
\end{abstract}

Keywords: collector angle; flow discharge; temperature difference; efficiency.

\section{PENDAHULUAN}

Di Indonesia minyak bumi merupakan pilihan utama untuk memenuhi kebutuhan energinya. Namun demikian, energi ini akan habis karena ketersediaanya yang terbatas dan termasuk energi tidak terbarukan. Energi minyak bumi atau energi fosil memiliki efek negatif terhadap lingkungan karena menyebabkan polusi udara dan juga mempercepat global warming [1-3]. Oleh sebab itu perlu dicari usaha-usaha penggunaan atau pemanfaatan energi alternatif.

Salah satu energi alternatif adalah energi matahari/surya. Energi surya merupakan energi yang melimpah dan gratis di Indonesia [4]. Namun demikian, energi surya tersebut tidak seluruhnya sampai di permukaan bumi. Oleh sebab itu, perlu dibuat alat pengumpul energi surya yaitu solar kolektor. Menurut Rosa [5], panjang gelombang radiasi surya tidak semuanya dapat diserap oleh absorber. Panjang 
gelombang yang mampu diserap biasanya berkisar dari 0,29 sampai dengan 2,5 $\mu \mathrm{m}$. Salah satu komponen kolektor surya adalah absorber yang harus dibuat dari material yang mempunyai konduktivitas termal tinggi. Permukaannya bisa bergelombang atau datar. Selain pelat penyerap, kolektor surya juga tersusun atas isolator dan penutup tembus cahaya seperti kaca.

Cara untuk meningkatkan energi berguna (useful energy) adalah dengan menvariasikan kemiringan alat kolektor tersebut. Efek dari kemiringan kolektor untuk water heater sudah dilakukan oleh peneliti sebelumnya yaitu Wilis dan Santosa [6]. Sudut kemiringan yang mereka gunakan adalah $0^{\circ}, 15^{\circ}$ dan $20^{\circ}$. Mereka memperoleh hasil bahwa efisiensi yang tertinggi diperoleh oleh kolektor dengan kemiringan $15^{\circ}$. Namun demikian, secara umum kemiringan atap rumah adalah sekitar $30^{\circ}$ sehingga kolektor yang diteliti diletakan pada sudut $30^{\circ}$ dan divariasikan dengan sudut-sudut yang lain. Oleh sebab itu, tujuan penelitian ini adalah menginvestigasi apakah efek kemiringan kolektor secara siknifikan berdampak terhadap kinerja kolektor.

\section{METODOLOGI PENELITIAN}

Metode penelitian yang digunakan adalah eksperimental dengan menggunakan beberapa variabel bebas dan variabel terikat. Hasil uji dianalisis untuk menjawab permasalahan yang ada serta hasil penelitian disajikan dalam bentuk grafik atau tabel agar memudahkan pemahaman.

\subsection{Fasilitas dan Prosedur}

Skema alat penelitian ditunjukan pada gambar 1 yang komponennya adalah pompa, bak penampung, pipa selang, pipa tembaga, pipa overflow, kolektor surya, stop keran, stopwatch, pyranometer, anemometer dan gelas ukur. Pipa tembaga yang dipasang pada absorber berbentuk paralel dengan tujuh pipa tembaga berdiameter $1 / 2$ inci. Bentuk susunan pipa paralel dipilih karena menurut penelitian sebelumnya dikatakan bahwa heat exchanger dengan pipa paralel lebih bagus dari pada berbentuk serpentin, Wirawan dkk. [1-2], Mirmanto dkk. [6-8]. Sedangkan foto alat penelitian disajikan pada gambar 2. Fluida yang digunakan pada penelitian ini adalah air bersih. Air mengalir secara grafitasi melalui pipa dari bak penampungan atas. Kemudian air mengalir menuju kolektor pelat datar dan memperoleh pemanasan di dalam kolektor tersebut. Laju aliran volume atau debit diatur dengan menggunakan stop keran dan diukur menggunakan gelas ukur dan stop watch.

Semua suhu air masuk, air keluar, suhu lingkungan dan suhu kolektor diukur dengan menggunakan termokopel tipe $\mathrm{K}$ yang telah dikalibrasi dengan toleransi $\pm 0,5^{\circ} \mathrm{C}$. Suhu bagian kolektor yang diukur adalah suhu tutup, suhu dinding, suhu absorber dan suhu pipa tembaga. Semua termokopel dihubungkan langsung dengan data logar NIDAQ9714 sehingga semua suhu dapat dicatat pada waktu yang bersamaan. Pompa yang digunakan adalah pompa akuarium. Pompa ini hanya digunakan untuk menaikan air dari bak bawah ke bak atas. Di bak atas terdapat pipa overflow yaitu digunakan untuk menjaga ketinggian permukaan air di bak atas tetap.

Pengujian dilakukan mulai pukul 10.00 Wita - 17.00 Wita. Air dialirkan naik dari bak bawah dengan menggunakan pompa secara kontinue. Dari bak atas, air mengalir secara alami karena perbedaan ketinggian menuju kolektor surya. Pada kolektor surya, air mengalami pemanasan hingga suhu tertentu, dan kemudian air keluar meninggalkan kolektor.

\subsection{Data Reduksi}

Energi yang masuk ke dalam kolektor dapat diestimasi dengan menggunakan persamaan (1) yang dapat diperoleh dari Duffie dan Beckman [9].

$Q_{\text {in }}=I b_{T} A_{c}$

$Q_{\text {in }}$ menyatakan aliran kalor yang diserap oleh kolektor (W), sedangkan $I b_{T}$ merupakan radiasi matahari per meter persegi $\left(\mathrm{W} / \mathrm{m}^{2}\right)$ dan $A_{c}$ menunjukan luas kolektor $\left(\mathrm{m}^{2}\right)$ tegak lurus dengan datangnya radiasi matahari. Persamaan tersebut juga telah digunakan oleh beberapa peneliti sebelumnya seperti yang dilakukan oleh Wirawan dkk. [1-2]. Disamping terdapat panas masuk, pada kolektor terdapat panas guna dan kerugian panas [10-13]. 


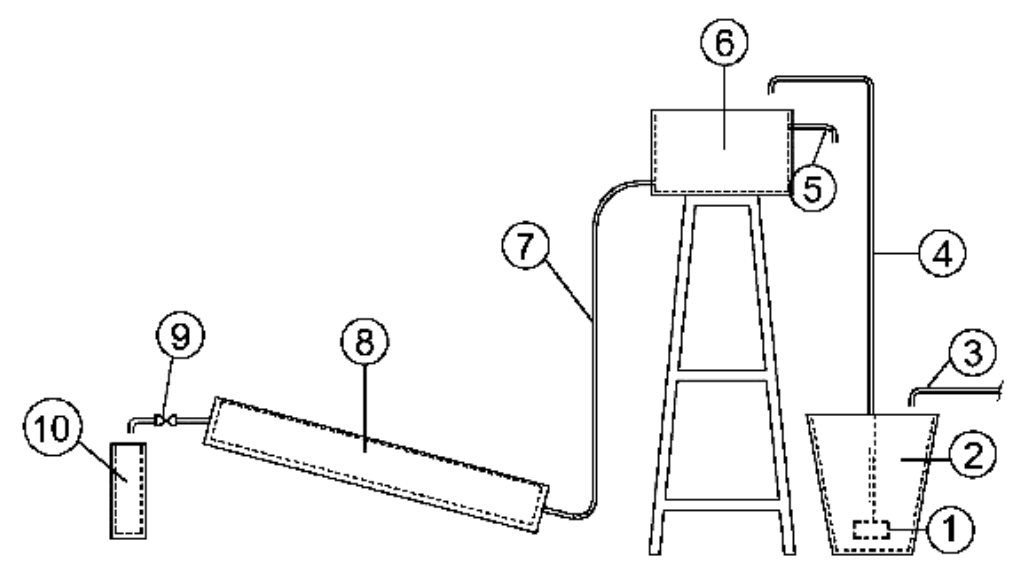

1. Pompa air, 2. Bak penampung bawah, 3. Kran sumber air, 4. Pipa pralon, 5. Pipa keluaran, 6. Bak penampung atas, 7. Pipa selang, 8. Kolektor surya batu granit, 9. Stop keran, 10. Volume ukur

\section{Gambar 1. Skema Alat Penelitian}

Panas yang diserap oleh air, $Q_{u s e}$, disebut dengan panas guna. Panas ini di dalam kolektor menyatakan panas yang diserap oleh air dan dibawa keluar kolektor dan merupakan perkalian dari laju aliran massa air, kapasitas panas air pada tekanan konstan, serta perbedaan suhu air masuk dan keluar $T_{i}$ dan $T_{o} . Q_{u s e}$ dapat diestimasi sebagai berikut, Wirawan dkk. [1-2] dan [10-13]:

$Q_{\text {use }}=\dot{m} c_{p}\left(T_{o}-T_{i}\right)$

$\dot{m}$ adalah mass flow rate $(\mathrm{kg} / \mathrm{s})$, sedangkan $c_{p}$ menunjukan panas jenis fluida $(\mathrm{J} / \mathrm{kgK})$. Radiasi matahari yang masuk permukaan kolektor, sebagian besar menjadi energi guna. Persamaan (2) juga digunakan oleh Wirawan dkk. [1-2] dan [10-13].

Disamping panas guna, kerugian panas dari kolektor juga merupakan variabel yang sangat penting. Kerugian panas ini, $Q_{\text {loss }}$, dapat diprediksi dengan persamaan (3) dan dapat ditulis sebagai:

$$
Q_{\text {loss }}=Q_{\text {in }}-Q_{\text {use }}
$$

Selain panas guna, kinerja kolektor pelat datar dapat dilihat dari parameter efisiensi. Efisiensi kolektor, $\eta$ merupakan perbandingan panas guna dengan panas radiasi matahari yang masuk, Wirawan dkk. [1-2], dan [10-13], Syamsu dkk. [14] dan dinyatakan dengan persamaan:

$$
\eta=\frac{Q_{u s e}}{Q_{\text {in }}}
$$

\section{HASIL DAN PEMBAHASAN}

Setelah melakukan percobaan dan mendapatkan data-data yang diperlukan maka langkah selanjutnya adalah melakukan perhitungan terhadap data-data yang sudah didapatkan dari hasil penelitian. Adapun perhitungan yang dilakukan adalah untuk mengetahui besarnya intensitas radiasi yang masuk ke kolektor $I b_{T}$, perbedaan temperatur air keluar dan masuk kolektor, $\Delta T$, besarnya kalor yang masuk, $Q_{i n}$, besarnya kalor yang digunakan, $Q_{u s e}$, besarnya kalor yang hilang, $Q_{\text {loss }}$ dan efisiensi dari kolektor, $\eta$.

Hasil perhitungan $Q_{\text {in }}$ dengan menggunakan persamaan (1) ditunjukan pada gambar 2. $Q_{\text {in }}$ yang diterima oleh kolektor dengan $15^{\circ}, 30^{\circ}$ dan $45^{\circ}$ hampir sama sebab grafik saling berimpitan. Namun demikian, $Q_{i n}$ yang tertinggi didominasi oleh kolektor surya dengan sudut kemiringan $30^{\circ}$. Hal ini disebabkan arah sinar matahari ke kolektor yang miring $30^{\circ}$ lebih tegak dibandingkan arah sinar matahari ke kolektor dengan sudut kemiringan yang lainya. Gambar 2 nampak tidak konsisten, pada jam-jam tertentu $Q_{\text {in }}$ yang didapatkan turun drastis atau sangat rendah. Hal ini dikarenakan kondisi langit yang terkadang mendung atau matahari tertutup awan. Hasil yang demikian juga ditemukan oleh Wirawan dkk. [1-2], dan [10-13]. Kondisi cerah dan berawan dari langit tidak dapat dihindari sebab itulah merupakan variabel terikat yang tidak dapat dikontrol. 


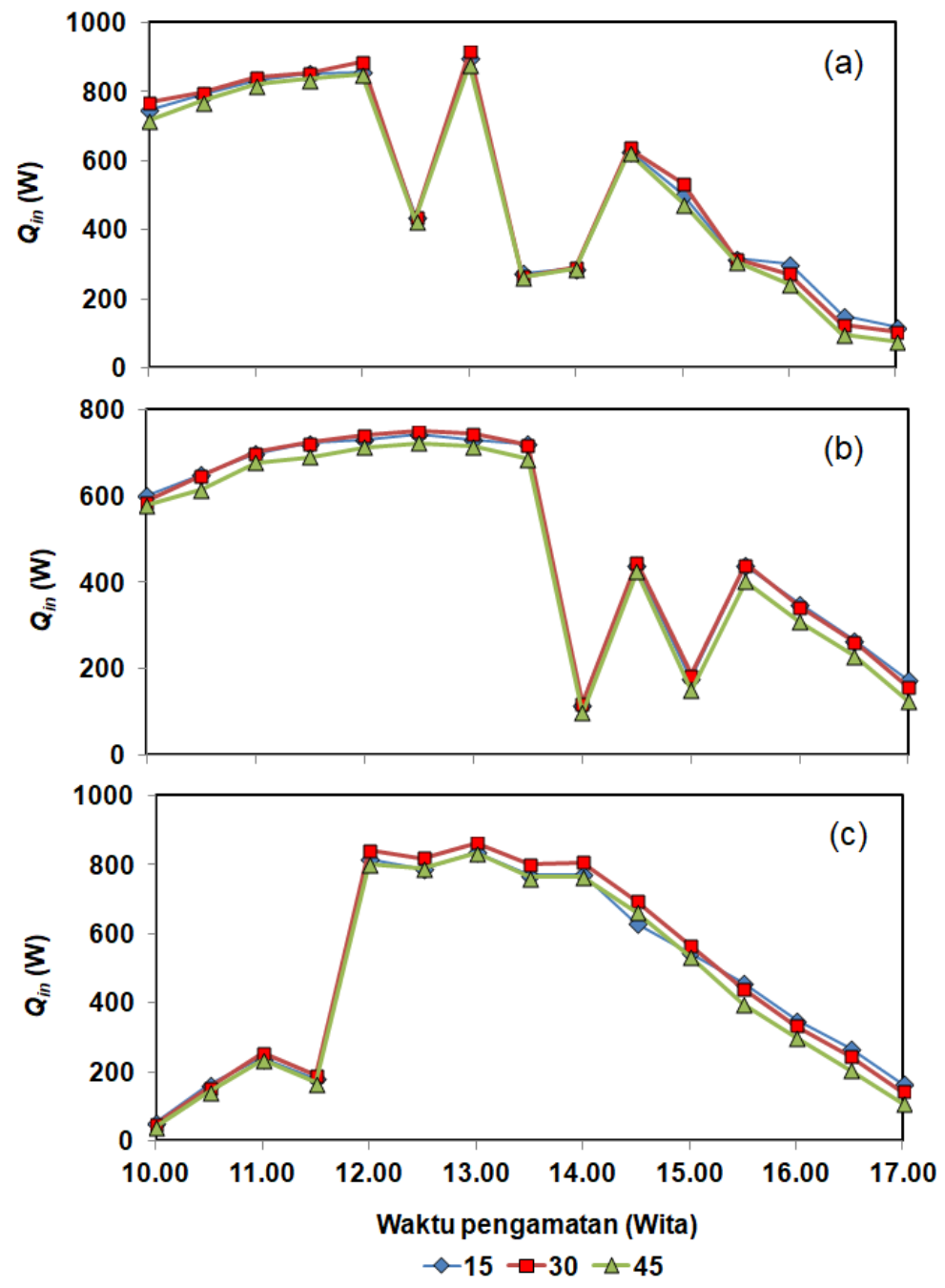

Gambar 2. Hubungan Qin dengan Waktu Penelitian, (a) 17 Juli 2017 pada Debit 300 cc/menit, (b) 19 Juli 2017 pada Debit 400 cc/menit, (c) 25 Juli 2017 pada 500 cc/menit. Angka 15, 30 dan 45 Menyatakan Kemiringan Kolektor $15^{\circ}, 30^{\circ}$ dan $45^{\circ}$.

Variabel perbedaan temperatur air masuk dan keluar disajikan pada gambar 3. Variabel ini nantinya digunakan untuk menentukan panas berguna $Q_{u s e}$. Perbedaan suhu ini dinyatakan dengan persamaan:

$$
\Delta T=T_{o}-T_{i}
$$

Hasil penggunaan persamaan (5) disajikan pada gambar 3. Seperti halnya dengan $Q_{i n}, \Delta T$ pun sangat berfluktuasi yang disebabkan oleh cuaca yang berubah-ubah. Pada awal-awal jam penelitian hingga jam 13.00 Wita, rata-rata $\Delta T$ naik, setelah jam tersebut pada umumnya $\Delta T$ turun sebab matahari sudah condong di sebelah barat hingga tidak nampak lagi. Namun demikian, gambar 3 mengidikasikan bahwa sudut kemiringan kolektor $30^{\circ}$ menghasilkan $\Delta T$ yang lebih tinggi.

Dengan $\Delta T$ yang tinggi, $Q_{u s e}$ akan tinggi pula. $Q_{u s e}$ dihitung dengan menggunakan persamaan (2). Persamaan tersebut juga digunakan oleh Wirawan dkk. [1-2], dan [10-13]. Hasil dari hitungan menggunakan persamaan (2) disajikan pada gambar 4. Gambar 4 pun menunjukan fluktuasi sebab $Q_{\text {in }}$ yang diterima kolektor telah berfluktuasi. Karena $\Delta T$ yang lebih tinggi untuk kemiringan kolektor $30^{\circ}$, maka $Q_{u s e}$ juga pada umumnya lebih tinggi dari pada $Q_{u s e}$ yang dihasilkan oleh kolektor dengan sudut kemiringan $15^{\circ}$ dan $45^{\circ}$. 

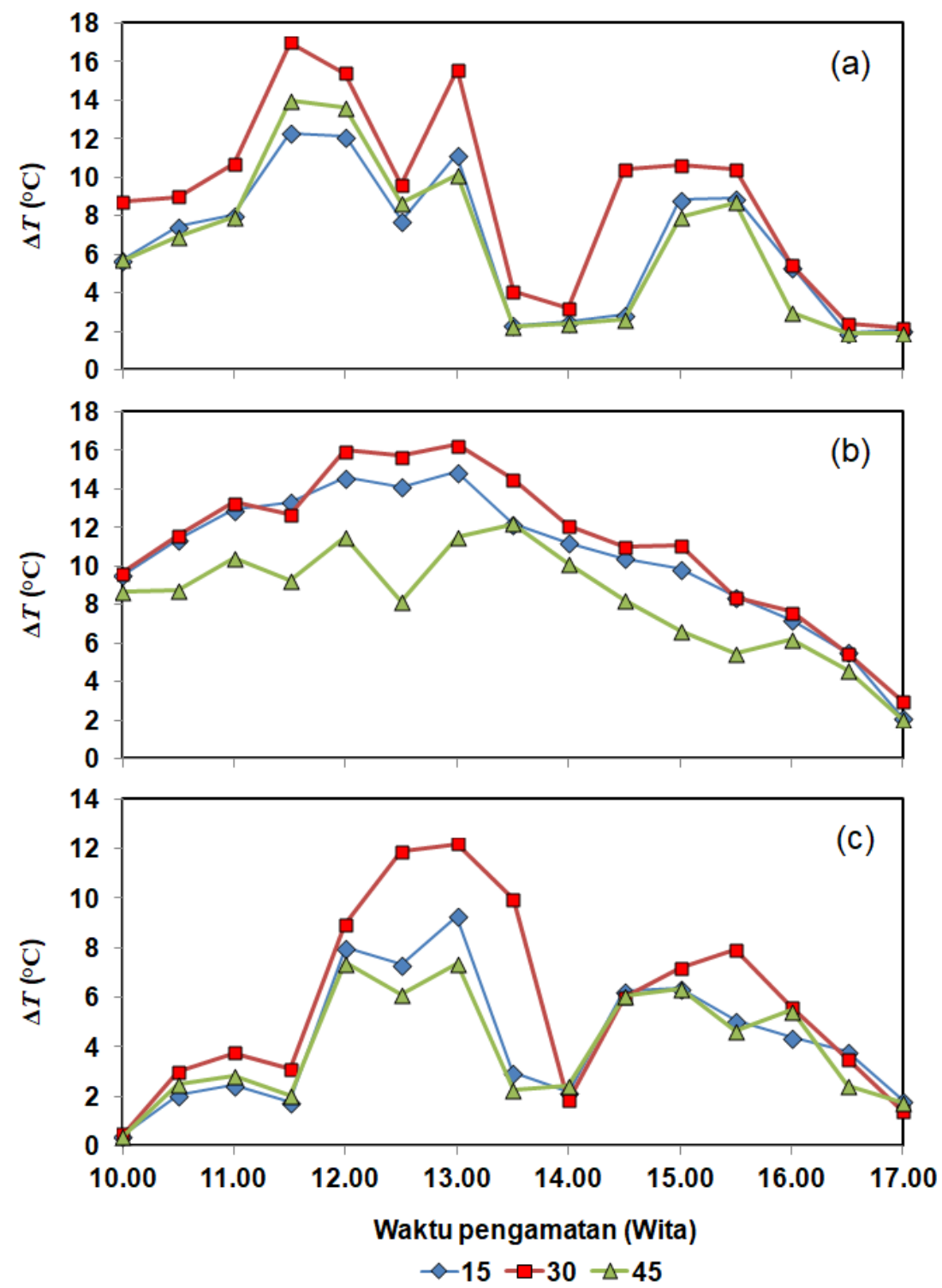

Gambar 3. Hubungan Antara $\Delta T$ dengan Waktu Pengamatan: (a) 17 Juli 2017 pada 300 cc/menit, (B) 19 Juli 2017 pada 400 cc/menit, dan (c) 25 Juli 2017 Pada 500 cc/menit

Untuk mengetahui pengaruh dari laju aliran volume, maka harus dibuat grafik $Q_{\text {use }}$ untuk sudut kemiringan yang sama tetapi berbeda laju aliran volumenya. Namun demikian, pada percobaan ini laju volume yang berbeda dites pada waktu yang berbeda pula sehingga $Q_{\text {use }}$ untuk laju aliran volume yang berbeda tidak dapat dibandingkan.

Unjuk kerja kolektor dapat pula dinyatakan dengan efisiensi kolektor [1-2, 10-13]. Parameter ini dihitung dengan menggunakan persamaan (4) dan hasil perhitunganya ditunjukan pada gambar 5. Gambar 5 menunjukan bahwa efisiensi rata-rata harian tertinggi dicapai oleh kolektor surya dengan sudut kemiringan $30^{\circ}$, kemudian diikuti oleh kolektor dengan sudut kemiringan $15^{\circ}$, dan efisiensi rata-rata harian terendah didapatkan dengan sudut kemiringan kolektor $45^{\circ}$. 

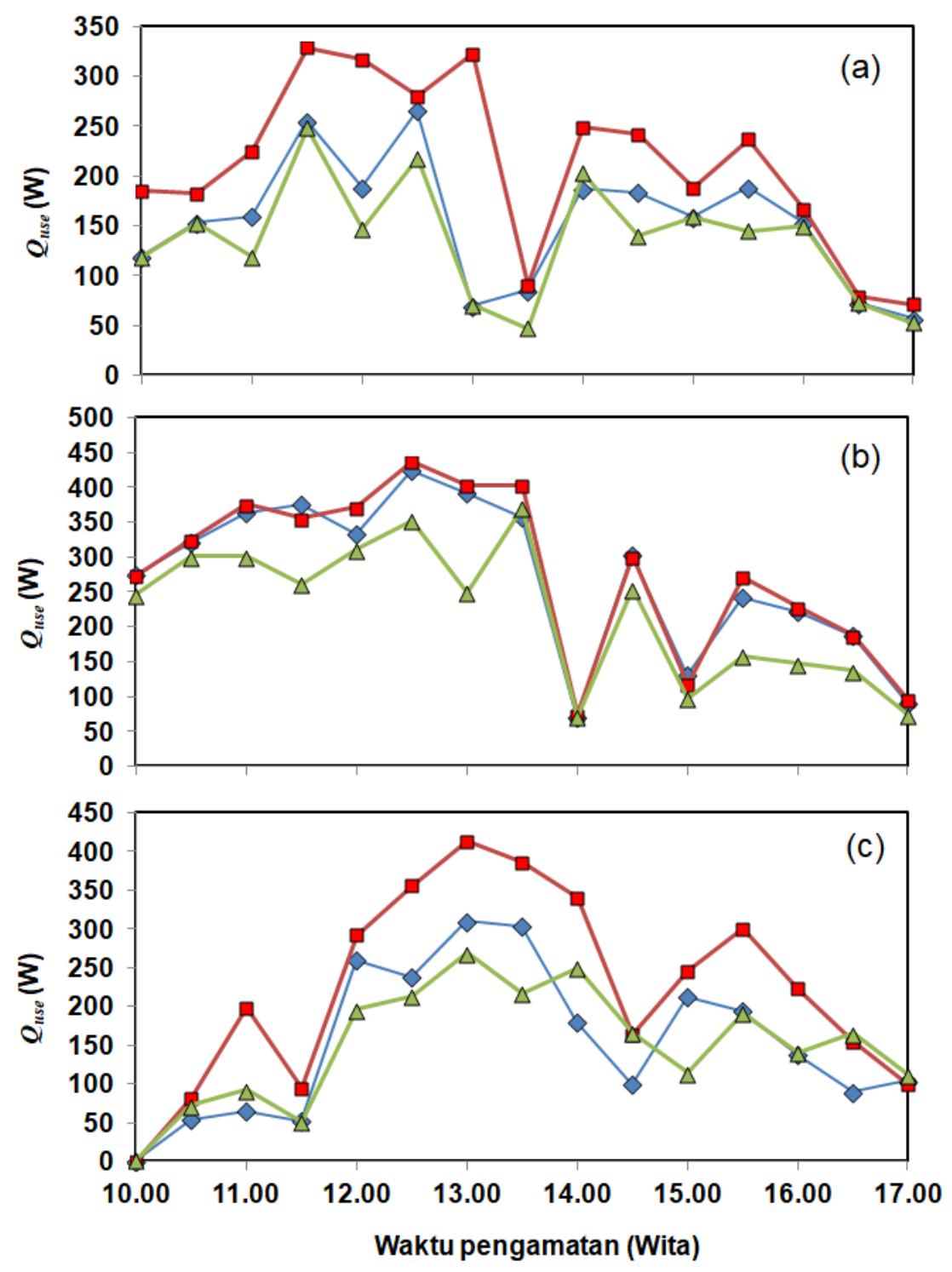

$\leadsto-15 \rightarrow-30-45$

Gambar 4. Hubungan Antara Quse dengan Waktu Pemgamatan: (a) 17 Juli 2017 pada 300 cc/menit, (b) 19 Juli 2017 pada 400 cc/menit, dan (C) 25 Juli 2017 pada 500 cc/menit

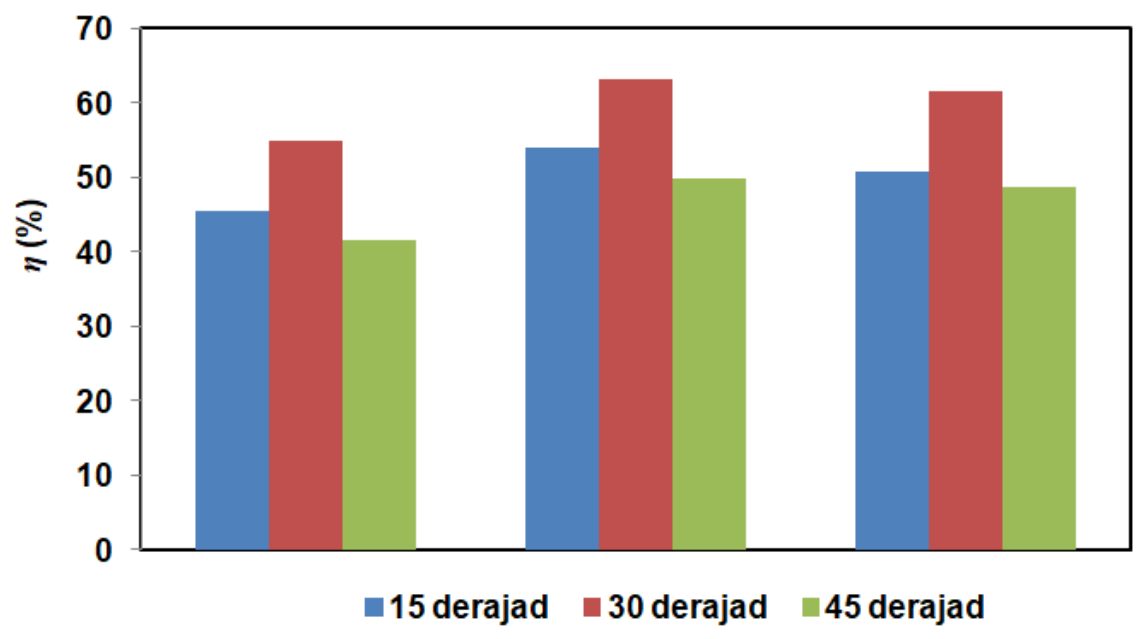

Gambar 5. Hubungan Antara Efisiensi Rata-rata Harian Terhadap Sudut Kemiringan Kolektor 


\section{KESIMPULAN}

Penelitian untuk mengetahui pengaruh kemiringan sudut kolektor terhadap unjuk kerja kolektor surya dengan absorber batu granit telah dilaksanakan. Dari hasi percobaan dan analisis data, beberapa pernyataan atau temuan yang dapat diperoleh. Panas masuk ke dalam kolektor surya yang diberi simbol $Q_{\text {in }}$ sangat fluktuatif tergantung pada cuaca (cerah atau mendung). Akibat dari fluktuasi panas masuk, maka $\Delta T$ juga berfluktuasi. $Q_{u s e}$ yang bergantung pada $\Delta T$ tentunya juga menjadi berfluktuasi. $\Delta T$ maupun $Q_{u s e}$ yang tertinggi diperoleh dengan kolektor surya dengan sudut kemiringan $30^{\circ}$. Efisiensi ratarata harian yang tertinggi juga didominasi oleh kolektor surya dengan sudut kemiringan $30^{\circ}$.

\section{UCAPAN TERIMA KASIH}

Diucapkan banyak terimakasih kepada DIKTI yang telah memberikan dana penelitian melalui DRPM program hibah Produk Terapan 2017.

\section{DAFTAR PUSTAKA}

[1] Wirawan, M., Mirmanto, Susana, I.G.B., Sutanto, R., 2015. "Pengaruh Susunan Pipa Laluan Terhadap Pemanfaatan Kalor pada Kolektor Surya Pelat Datar Absorber Granit", Dinamika Teknik Mesin, Vol. 5, No. 1, pp. 50-55.

[2] Wirawan, M., Kurniawan, R., Mirmanto, 2016. "Pengaruh Jumlah Haluan Pipa Paralel pada Kolektor Surya Pelat Datar Absorber Batu Kerikil Terhadap Laju Perpindahan Panas", Dinamika Teknik Mesin, Vol. 6, No. 2, pp. 127-133.

[3] Hoel, M., Kvemdokk, S., 1996. "Depletion of Fossil Fuels and The Impacts of Global Warming", Resource and Energy Economics, Vol. 18, pp. 115-136.

[4] Setyadi, U.D., Bambang Arip Dwiyantoro B.A., 2015. "Pengaruh Sudut Kemiringan Kolektor Surya Pelat Datar terhadap Efisiensi Termal dengan Penambahan Eksternal Annular Fin pada Pipa", Jurnal Teknik ITS, Vol. 4, No. 1, pp. 31-36.

[5] Rosa, Y., 2007. "Rancang Bangun Kolektor Pelat Datar Energi Surya untuk Sistem Pengering Pasca Panen", Jurnal Teknik Mesin, Vol. 4, No. 2, pp. 68-82.

[6] Mirmanto, Sayoga, I.M.A., Zulkarnain, 2016. "Pengaruh Debit Terhadap Unjuk Kerja Alat Penukar Kalor dan Penurunan Suhu Ruangan", Dinamika Teknik Mesin, Vol. 6, No. 1, pp. 1-7.

[7] Mirmanto, Syahrul, Sulistyowati, E.D., Okariawan, I.D.K., Rodian, 2017. "Effect of Inlet Temperature and Ventilation on Heat Transfer Rate and Water Content Removal of Red Chilies", Journal of Mechanical Science and Technology, Vol. 31, No. 3, pp. 1531-1537.

[8] Mirmanto, M., Sulistyowati, E.D., Okariawan, I.D.K., 2016. "Effect of Radiator Type on Dryer Room Temperature Distribution and Heat Transfer Rate", JP Journal of Heat and Mass Transfer, Vol. 13, No. 4, pp. 511-532.

[9] Duffie, J.A., Beckman, W.A., 1980. Solar Engineering Of Thermal Process $2^{\text {nd }}$ Edition, John Wiley \& Sons Inc., New York.

[10] Saputra, B.H., 2015. Pengaruh Jumlah Pipa Pada Kolektor Surya Absorber Batu Granit Terhadap Laju Perpindahan Panas, Skripsi, Jurusan Teknik Mesin, Fakultas Teknik, Universitas Mataram.

[11] Hamzanwadi, 2015. Pengaruh Jumlah Pipa Terhadap Laju Pelepasan Kalor pada Kolektor Surya Absorber Batu Granit, Skripsi, Jurusan Teknik Mesin, Fakultas Teknik, Universitas Mataram.

[12] Fahrurrozi, I., 2017. Pengaruh Variasi Sudut Kemiringan Kolektor Surya Plat Datar Absorber Batu Granit Terhadap Unjuk Kerja Kolektor, Skripsi, Jurusan Teknik Mesin, Fakultas Teknik, Universitas Mataram.

[13] Wilis, G.R., Santosa, I., 2014. "Variasi Sudut Kemiringan Kolektor Surya Solar Water Heater", Prosiding Seminar Nasional Aplikasi Sains \& Teknologi (SNAST), Yogyakarta. 
Jurnal SIMETRIS, Vol. 9 No. 2 November 2018

P-ISSN: 2252-4983, E-ISSN: 2549-3108

[14] Syamsu, W.D., Selleng, K., Mustofa, 2012. "Efektifitas Kolektor Energi Surya pada Konfigurasi Paralel-Serpentine", Majalah Ilmiah MEKTEK, No. 1, pp. 12-16. 